\title{
Sistem Pengusir Hama Burung dan Hama Tikus Pada Tanaman Padi Berbasis Raspberry pi
}

\author{
Robby Juniansyah Arifandi ${ }^{1}$, Mochammad Junus ${ }^{2}$, Mila Kusumawardani ${ }^{3}$ \\ 1,2,3 Program Studi Jaringan Telekomunikasi Digital, \\ Jurusan Teknik Elektro, Politeknik Negeri Malang, Indonesia \\ 1robbyjuniansyah647@gmail.com, ${ }^{2}$ mochammad.junus@polinema.ac.id, ${ }^{3}$ mila.kusumawardani@polinema.ac.id
}

\begin{abstract}
Pests are one of the main enemies of rice farmers who at any time can attack crops. The impact of rice pest attacks can reduce the production of rice crops, causing crop yields to decline. One of the pests that often unsettling rice farmers is bird pests (Passer spp.) and rats (Hundred argentiventer), the pest attack is determined by the state of the climate, and the unwise use of insecticides and the manual expulsion of pests takes a lot of time. To reduce the above problems in this study will develop new innovations in agriculture, through The Repellent Tool Automatically is one way to help rice farmers to pollute the environment and expulsion manually. In this tool is installed a micro controller raspberry pi 3 as a link between the pear sensor and the camera module, in addition raspberry pi 3 is integrated with the smartphone application in real-time for the process of monitoring the presence of pests and using speakers to repel pests. The test results obtained by rat pests are disturbed when the speakers emit an ultrasonic wave frequency of $34-45 \mathrm{KHz}$ and bird pests will be disturbed if the speakers emit a frequency of $60 \mathrm{kHz}$. The PIR sensor can detect the presence of rat pests with a vulnerable distance of 5-50cm, while the camera detects the movement of bird groups and gets an accuracy percentage of $44.4 \%$ of the test results and an average delay of 1.08 seconds.
\end{abstract}

Keywords-Pest, Ultrasonic Waves, PIR sensor, Camera.

Abstrak-Hama merupakan salah satu musuh utama para petani padi yang setiap saat bisa menyerang tanaman. Dampak dari serangan hama padi dapat mengurangi produksi tanaman padi sehingga menyebabkan hasil panen menurun. Salah satu hama yang kerap meresahkan petani padi adalah hama burung (Passer spp.)dan tikus (Ratus argentiventer), terjadinya serangan hama ini ditentukan oleh keadaan iklim, dan penggunaan insektisida yang tidak bijaksana dan pengusiran hama secara maual yang membutuhkan banyak waktu. Untuk mengurangi masalah diatas pada penelitian ini akan mengembangkan inovasi baru dalam bidang pertanian, melalui Alat Pengusir Hama Secara Otomatis merupakan salah satu cara untuk membantu para petani padi untuk pencemaran lingkungan dan pengusiran secara manual. Pada alat ini dipasang sebuah mikro kontroler raspberry pi 3 sebagai penghubung antara sensor pir dan kamera, selain itu raspberry pi 3 di integrasikan dengan aplikasi smartphone secara realtime untuk proses monitoring keberadaan hama dan menggunakan speaker untuk mengusir hama. Hasil pengujian yang didapat hama tikus terganggu ketika speaker mengeluarkan frekuensi gelombang ultrasonik 34-45 KHz dan hama burung akan terganggu jika speaker mengeluarkan frekuensi $60 \mathrm{kHz}$. Sensor PIR dapat mendeteksi keberadaan hama tikus dengan rentan jarak 5-50cm, sedangkan kamera deteksi gerakan kelompok burung dan mendapatkan persentase akurasi hasil pengujian $44,4 \%$ dan rata - rata delay 1.08 detik

Kata kunci- Hama, Gelombang Ultrasonik, Sensor PIR, Modul Kamera.

\section{PENDAHULUAN}

Indonesia merupakan negara agraris yang sebagian besar lahan digunakan untuk pertanian. Pada sektor pertanian Indonesia memiliki beragam jenis tanaman, hal ini didukung kondisi iklim tropis yang berbeda, dalam bidang tanaman pangan di Indonesia memiliki tanaman unggul seperti padi, jagung, kedelai, kedelai, kacang tanah, ubi kayu dan berbagai jenis faritas yang lain.[1] Produktivitas tanaman padi sebagai jenis tanaman pangan yang paling dibutuhkan di Indonesia, berdasarkan Badan Pusat dan Statistika (BPS) total produksi beras di Indonesia dari Januari-Desember 2018 diperkirakan mencapai 32,42 juta ton sedangkan konsumsi beras domestik mencapai 29,57 juta ton[2]. Namun, untuk tiga bulan terakhir tahun 2018 produksi beras diperkirakan turun dan hanya mencapai 3,94 juta ton sementara konsumsi sebesar 7,45 juta ton sehingga terjadi defisit sekitar 3,51 juta ton[3].

Salah satu faktor penyebab defisit pada beberapa bulan diakibatkan oleh serangan hama, tanaman padi di Indonesia sudah rentan (lemah) terhadap serangan hama. Hama utama yang sering merusak padi diantara lain seperti burung dan tikus sehingga petani merasakan perlunya penanggulangan atas adanya hama tersebut. Untuk mengurangi intensitas serangan hama padi maka diperlukan sarana yang mendukung agar dapat mencapai hasil yang mencukupi kebutuhan nasional dalam bidang pangan dan meningkatkan perekonomian nasional. Saat ini sudah banyak alat mekanik yang digunakan untuk mengusir hama tanaman padi.

Dari permasalahan tersebut akan dibuat sistem telekontrol pengusir hama. Dengan menggunakan kamera untuk mendeteksi adanya burung dan sensor PIR untuk mendeteksi pergerakan tikus. Ketika kamera dan sensor PIR mendeteksi adanya hama, dalam hal ini adalah burung dan tikus maka ketika terdeteksi adanya hama secara otomatis sistem akan mengaktifkan gelombang ultrasonik. Frekuensi gelombang ultrasonik yang digunakan dengan rentang $1 \mathrm{khz}-72 \mathrm{khz}$, sehingga suara speaker menyebar ke segala arah yang dapat menggangu pendengaran hama, dan menggunakan rasbperry pi 3 sebagai kontrol utama hardware. Selain itu terdapat aplikasi android yang terintegrasi dengan perangkat hardware. Ketika hama terdeteksi maka langsung mengirimkan notifikasi kepada 
Smartphone pemilik sawah yang memudahkan monitoring tanaman padi dari serangan hama tikus dan burung.

\section{METODE}

Bagian ini menjelaskan secara rinci tentang penelitian yang dilakukan.

\section{A. Blok Diagram Sistem}

Rancangan yang akan dilakukan pada penelitian ini akan ditunjukkan pada Gambar 1.

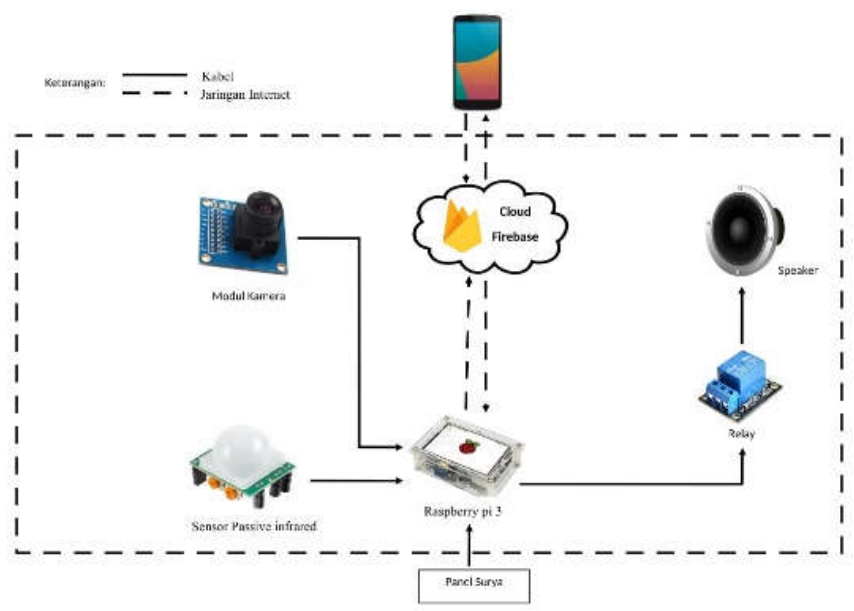

Gambar 1. Blok diagram sistem

Gambar 1 menjelaskan tentang diagram blok sistem pada penelitian ini ;

- Sensor HC-SR501 digunakan sebagai pendeteksi keberadaan tikus pada tanaman padi di area persawahan.

- Modul Kamera Ov76 digunakan sebagai pendeteksi keberadaan burung yang merusak tanaman padi di area persawahan.

- $\quad$ Raspberry Pi 3 berfungsi sebagai pusat kontrol utama yang mengolah dan menjalankan semua proses hasil output dan hasil input. Selain itu juga terkoneksi dengan wifi agar dapat diintegrasikan dengan aplikasi yang terinstal pada handphone.

- Speaker sebagai output yang menghasilkan audio gelombang ultrasonik sehingga dapat mengganggu pendengaran hama burung dan tikus.

- Smartphone berfungsi untuk menerima notifikasi adanya hama tikus dan burung yang merusak tanaman padi.

\section{B. Perencanaan Hardware}

Pada perencanaan hardware gambar 2 menunjukkan skema rangkaian dari alat pengusir hama padi, untuk mendeteksi pergerakan hama tikus menggunakan sensor pir dan dapat diaktifkan dengan cara menghubungkan pin output sensor pir dengan pin gpio 18 pada raspberry pi. Modul kamera terhubung dengan port usb pada raspberry pi agar dapat mendeteksi keberadaan hama burung pada area persawahan.

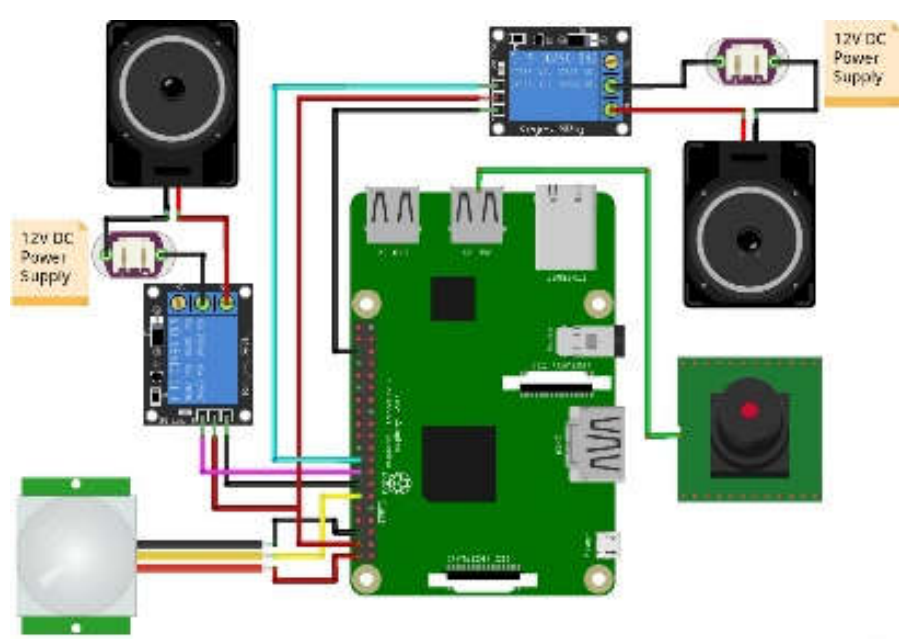

Gambar 2 Perancangan desain hardware

Hasil output dikontrol menggunakan relay yang bertugas sebagai switching menggunakan pin digital pada raspberry pi diantaranya, pin gpio23 merupakan relay untuk speaker pengusir hama tikus, pin gpio 24 digunakan sebagai relay spekaer pengusir hama burung. Data dari sensor pir dan modul kamera yang terhubung ke raspberry pi akan dikirimkan ke firebase sehingga dapat diakses menggunakan smartphone.

\section{Perencanaan Aplikasi}

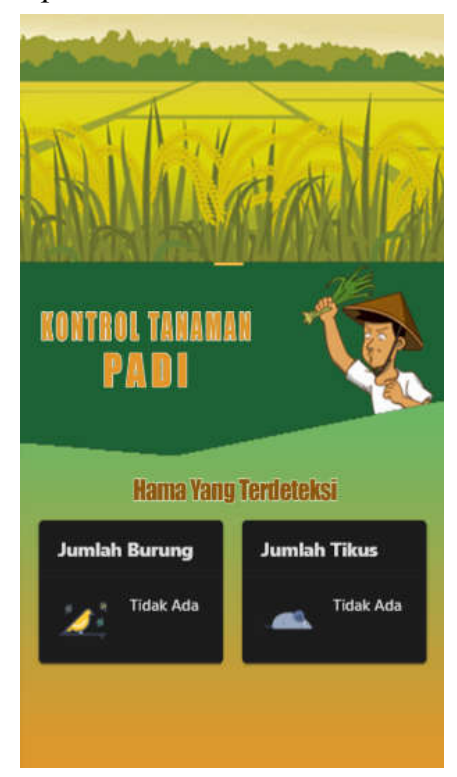

Gambar 3. Halaman awal

Gambar 3 menunjukkan rancangan desain aplikasi yang dibuat pada sistem adalah:

Aplikasi sistem monitoring pengusir hama padi ini dapat mendeteksi dua jenis hama, pertama mendeteksi hama keberadaan hama burung dan kedua mendeteksi keberadaan hama tikus. Proses pengambilan data pada aplikasi ini seacara real time sehingga keberadaan hama tikus dan burung dapat dimonitoring setiap waktu oleh petani padi. 


\section{HASIL DAN PEMBAHASAN}

\section{A. Hasil Rangkaian Hardware}

Gambar 4 menunjukkan rangkain pengusir hama tikus. Dalam rangkaian tersebut terdiri dari sensor pir untuk mendeteksi keberadaaan hama tikus, raspberry pi digunakan sebagai kontrol utama, modul relay sebagai switch on/off untuk menyalakan speaker dan terakhir speaker yang berfungsi sebagai output yang dapat mengeluarkan gelombang ultrasaonik.

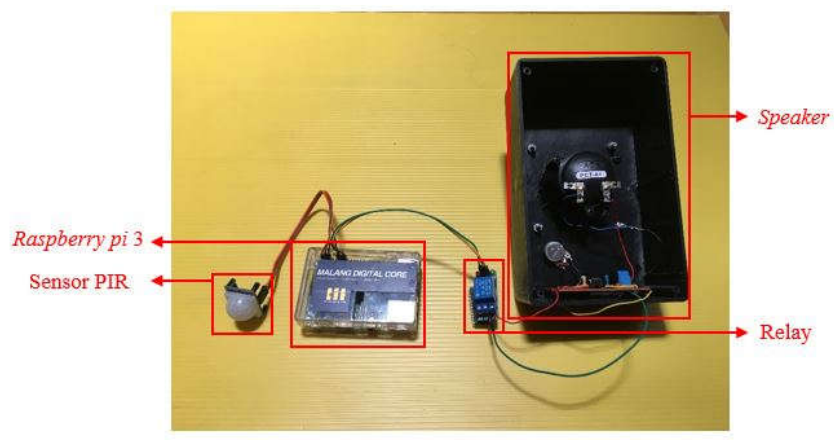

Gambar 4 Rangkaian pengusir hama tikus

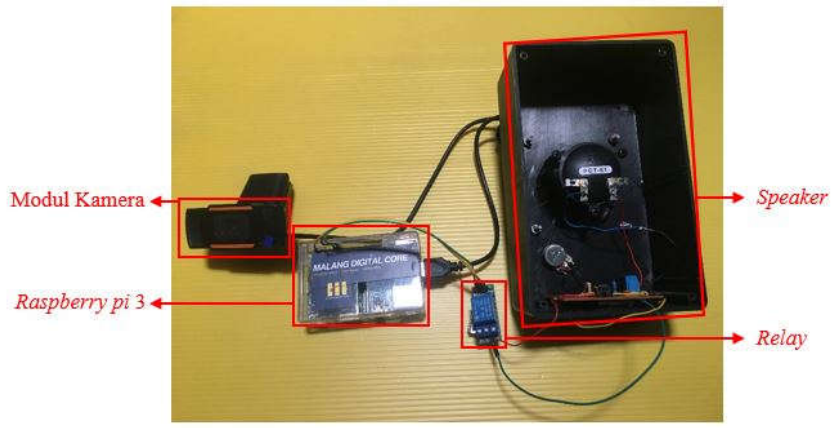

Gambar 5 Rangkaian pengusir hama burung

Gambar 5 menunjukkan rangkain pengusir hama burung. Dalam rangkaian tersebut terdiri dari modul kamera untuk mendeteksi keberadaaan hama burung, raspberry pi digunakan sebagai kontrol utama, modul relay sebagai switch on/off untuk menyalakan speaker dan terakhir speaker yang berfungsi sebagai output yang dapat mengeluarkan gelombang ultrasonik

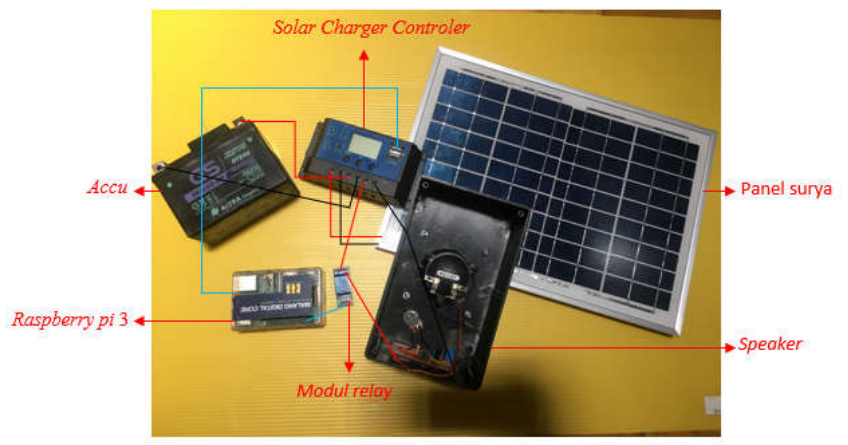

Gambar 6 Catu daya rangkaian pengusir hama padi

Gambar 6 memperlihatkan catu daya rangkian secara keseluruhan, panel surya sebagai sumber catu daya. Pada penelitian ini menggunakan panel surya yang memiliki Rated maximum power (Pin) $10 \mathrm{Wp}$ dan menghasilkan Voltage at Pmax (Vmp) 17V. Tegangan yang dihasilkan Panel surya akan disimpan di accu 12V DC dengan menggunakan SSC (solar charger controler) agar tidak pengisisan accu tidak menjadi berlebihan yang dapat merusak accu, kemudian scc mengalirkan tegangan 5V DC untuk rapberry pi 3 ,sesor pir, modul kamera dan modul relay terhubung ke speaker yang berfungsi sebagai output untuk mengeluarkan gelombang ultrasonik.

\section{B. Pengujian Speaker}

Perbandingan titik koordinat bertujuan untuk mengetahui keakurasian koordinat yang terbaca oleh alat ukur jika dibandingkan dengan GPS garmin dan G-Nettrack Pro. Data diperoleh dengan cara diam pada titik yang telah ditentukan.

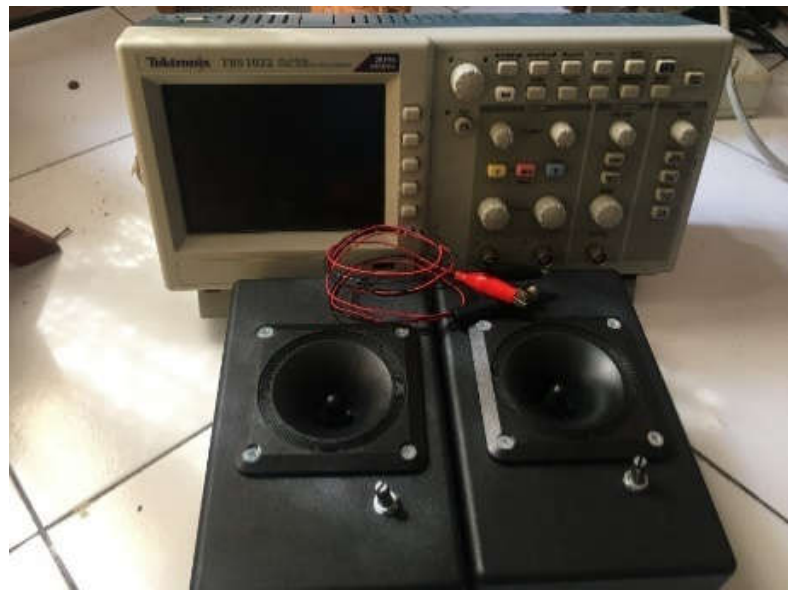

Gambar 7 Pengujian speaker

Setelah dilakukan pengujian seperti gambar 7 menunjukkan bahwa proses pengujiaan speaker dengan oscilloscope berhasil karena nilai frekuensi yang dihasilkan sama dengan perhitungan dengan rumus frekuensi IC 555 yaitu menghasilkan frekuensi $1 \mathrm{kHz}-72 \mathrm{kHz}$. Nilai keluaran frekuensi pada alat tidak sepenuhnya menampilkan nilai presisi, hal ini disebabkan rotary potensiometer sangat sensitif dengan pergerakan. Penggunaan IC juga memengaruhi kestabilan nilai keluaran frekuensi ultrasonik yang dapat disebut noise.

\section{Pengujian Jarak Sensor PIR}
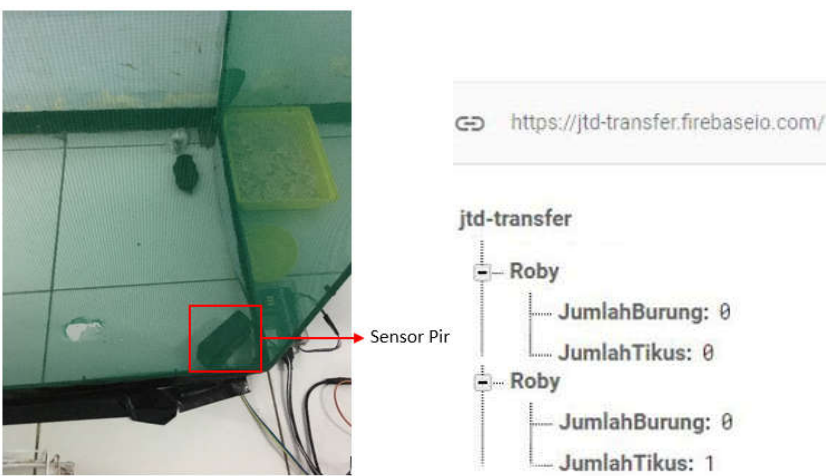

Gambar 8 Pengujian jarak sensor PIR 
Gambar 8 menunjukkan bahwa pengujian sensor PIR dapat mendeteksi keberadaan hama tikus dalam keadaan tertentu, misalnya karena jarak yang dekat dan kecepatan tikus saat berjalan. Sensor PIR hanya akan mengeluarkan logika 0 dan 1. 0 saat sensor tidak mendeteksi adanya perubahan pancaran infra merah dan 1 saat sensor mendeteksi infra merah. Hasil pengujian sensor PIR dijarak 5-50cm menunjukkan sensor PIR dapat mendeteksi keberadaan hama tikus, dapat dilihat pada tampilan firebase menunjukkan jumlah tikus "1". Namun berbeda keadaan saat tikus melewati sensor PIR pada jarak $55 \mathrm{~cm}-70 \mathrm{~cm}$, tampilan firebase menunjukkan jumlah tikus " 0 " menandakan bahwa sensor tidak mendeteksi pergerakan tikus.

\section{Pengujian Modul Kamera}

Berikut hasil pengujian akurasi deteksi objek yang ditunjukan pada gambar 9

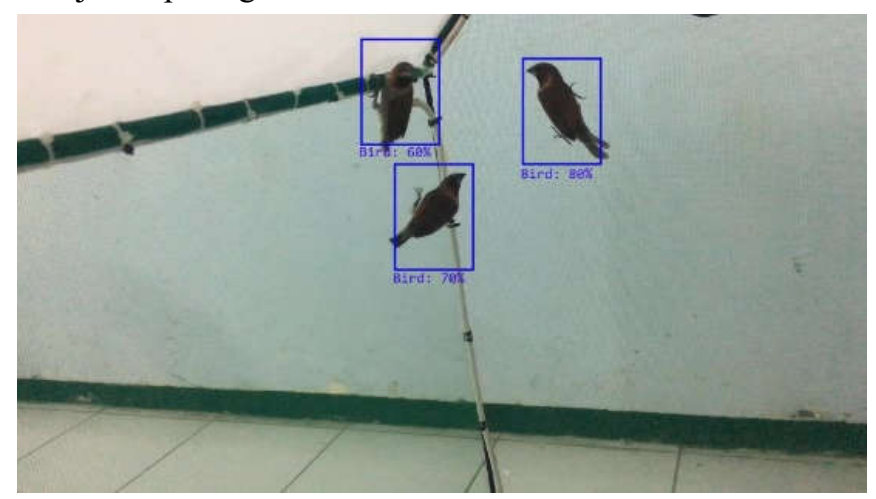

Gambar 9 pengujian modul kamera

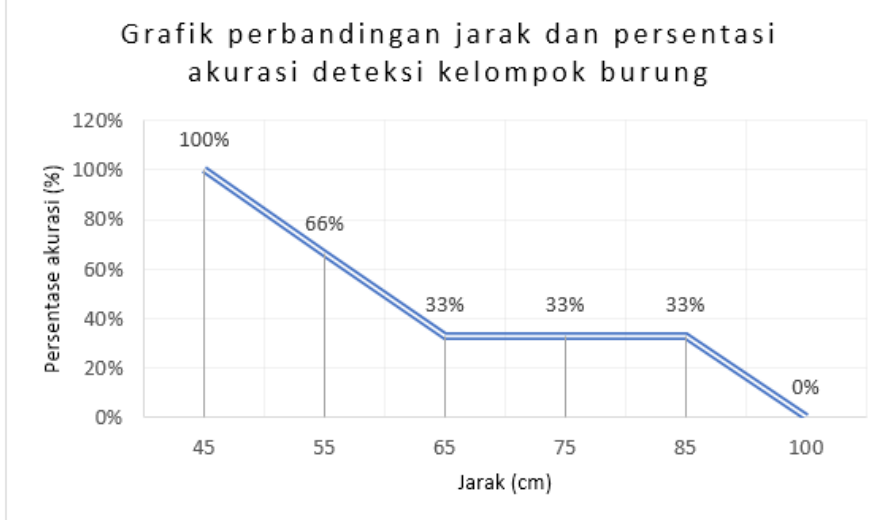

Gambar 10 Grafik perbandingan jarak dan akurasi deteksi kelompok burung

$$
\begin{aligned}
& \text { Rumus rata - rata delay }=\frac{(\text { Jumlah nilai })}{\text { Banyaknya nilai }} \\
& \text { Presentase Akurasi }=\frac{(1]}{\text { Jumlah burung burung })} \\
& =\frac{3}{3} \times 100 \% \\
& =100 \%
\end{aligned}
$$

Gambar 10 menunjukkan pengujian dengan menggunakan metode SSD. Pada pengujian akurasi dapat mendeteksi pergerakan burung yang cepat saat berada dialam bebas. Dari hasil pengujian ini didapatkan hasil terbaik pada jarak $45 \mathrm{~cm}$ dengan presentase keberhasilan $100 \%$ dan rata - rata delay yang didapatkan adalah 1 detik.

\section{KESIMPULAN}

Pembuatan sistem pengusir hama padi dapa diintegrasikan dengan smartphone menggunakan mikrokontroler raspberry pi 3 sebagai penghubung antara sensor pir dan kamera usb. Selain itu raspberry pi 3 juga terhubung dengan internet untuk mengirimkan data dari sensor pir dan kamera ke firebase. Ketika sensor pir mendeteksi keberadaan hama tikus dan kamera mendeteksi keberadaan hama burung maka secara realtime akan mengirimkan notifikasi ke aplikasi android.

Pengaruh frekuensi pada gerakan kelompok burung dan tikus berdasarkan suara yang dikeluarkan oleh speaker. Pada frekuensi $35-45 \mathrm{KHz}$ hama tikus mengalami terganggunya aktivitas dan menjauhi gelombang suara, sedangkan hama burung cenderung terbang menjauhi gelombang suara pada frekuensi $60 \mathrm{KHz}$ pada jarak dan waktu pemaparan yang sama yakni $50 \mathrm{~cm}$ dan 20 menit sampai 30 menit waktu pemaparan gelombang ultrasonik.

Pengujian mulai dari jam 6-10 pagi dan jam 2-6 sore didapatkan hasil kualitas sistem pengujian disawah, sensor pir dapat mendeteksi keberadaan hama tikus dengan rentan jarak $5-50 \mathrm{~cm}$. Kamera deteksi gerakan kelompok burung dan mendapatkan persentase akurasi hasil pengujian $44,4 \%$ dan rata - rata delay 1.08 detik. Semakin banyak objek yang terdeteksi membuat proses delay semakin besar karena data yang di proses semakin banyak. Sedangkan jarak berpengaruh terhadap persentase akurasi semakin jauh jarak objek dengan kamera membuat persentase akurasi semakin kecil.

\section{REFERENSI}

[1] "Sektor pertanian di indonesia dan potensi nya". [Online]. Tersedia: https://www.fulldronesolutions.com/sektorpertanian-di-indonesia-dan-potensi-nya-perkembanganinovasi-modern-tradisional/. [Diakses: 8 Oktober 2019].

[2] "Inilah Struktur Biaya Produksi Padi Indonesia", 2019. [Online]. Tersedia: :https:// databoks.katadata.co.id/datapublish/2018/05/04/inilahstruktur-biaya-produksi-padi-indonesia. [Diakses: 8 Oktober 2019].

[3] Leony Darmadi, "Kebijakan Percepatan Produk Benih VUB Padi di BBP2TP”. [Online]. Tersedia: https://slideplayer.info/slide/12206203/. [Diakses: 8 Oktober 2019].

[4] Sopialena (2017). "Segitiga Penyakit Tanaman", hal - 27. Samarinda. Mulawarman University. [Diakses :8 Oktober 2019].

[5] "Pelatihan Tentang Pengendalian Hama Wereng pada Tanaman Padi”. [Online]. Tersedia:https:/www.kompasiana.com/supebrianto6755 3/5cb233eaa8bc155a76715657/pelatihan-tentangpengendalian-hama-wereng-pada-tanaman-padi. [Diakses: 8 Oktober 2019]. 